\title{
Preliminary Analysis of Helicopter Options to Support Tunisian Counterterrorism Operations
}

\author{
Christopher A. Mouton and Adam R. Grissom
}

\section{Key findings}

- Four helicopters could be more cost-effective than the UH-60M: the AS-332L1 Super Puma, the CH-47D Chinook, the Mi-17v5, and the S-61T.

- Availability will also be a factor in determining whether these helicopters are viable alternatives.

\section{Background}

In early 2014, the government of Tunisia requested permission from the government of the United States to purchase $12 \mathrm{UH}$ $60 \mathrm{M}$ Blackhawk helicopters from Sikorsky to fulfill a number of roles in counterterrorism operations. Rising costs and delays in delivery raised the question of whether other cost-effective options exist to meet Tunisia's helicopter requirement.

\section{Approach}

Our team conducted a preliminary assessment of alternative

helicopters for counterterrorism air assault missions. Any decision to acquire an aircraft must consider many factors, including technical effectiveness, cost, maintainability, production-line capacity, training and support availability, industrial offsets, and domestic and international political implications. In this preliminary analysis, we focus on the question of cost-effectiveness in the UH-60M's primary role: Which alternative platforms could perform the assault mission, and at what cost?

The core of our analysis is detailed modeling of key "mission tasks" on a sortie-by-sortie basis. Our model uses raw technical data— such as specific range, hover performance, and weight limits— to simulate the flight of each alternative platform through each sortie. This enables us to assess which platforms can perform the required sorties, as well as how many aircraft are needed. The results serve as an input to our cost model. Using standard U.S. Department of Defense costing methods, we then estimate the cost of acquiring and operating the required number of each alternative helicopter, thereby comparing with each fleet option the cost of producing a given level of effectiveness. ${ }^{1}$

For this preliminary analysis, we were obliged to make five sets of assumptions about planning factors that we would normally derive from supporting analysis:

- The primary mission task is assault support to the Tunisian Special Forces Brigade and to other commando and special unit elements.

- The ground element is a typical counterterrorism (CT) strike force of 50 personnel, composed of elements for cordon, breach and clear, exploitation, and command and control. Each helicopter must be capable of carrying eight or more passengers on each mission task to maintain unit cohesion.

- The mission task is movement of the entire assault element to the landing zone in a single mission, or "turn." Transit is at medium altitude with a standard assault approach, out-of-ground-effect hover during the insertion, and retrograde of the assault element and detainees on mission completion. 
- The missions originate and terminate at Tunisian military airfields (Bizerte, Gafsa-Ksar, Sfax-Thyna, and Remada), TunisCarthage International Airport, or El Borma Airfield (Figure 1, left).

- The geographic pattern of operations is consistent with recent trends, with CT assaults potentially occurring anywhere in the country. We selected a broad sample of 69 landing zones that are typical potential targets for a CT campaign: compounds in isolated areas, beddown locations along roads and tracks in border areas, and small settlements in complex terrain (Figure 1, right; examples shown in Figure 2).

\section{Analysis}

For each of the 69 mission-task routes in Figure 1, we calculated the number of helicopters needed to meet the mission requirements. By combining this with the 20-year net-present-value life-cycle cost, we were able to derive the cost-effectiveness of each platform. A cost-effectiveness of 1.0 means that an equally effective alternative fleet would cost the same as a UH-60M fleet, a cost-effectiveness of 2.0 means that the equally effective alternative fleet would cost half as much, and a cost-effectiveness of 0.5 means that the equally effective alternative fleet would cost twice as much. Because of the error inherent in cost estimation and effectiveness modeling, we consider anything between 0.85 and 1.15 to be as cost-effective as the UH-60M.

The results of our preliminary analysis are shown in Figure 3. The results show four helicopters that could be more cost-effective than the UH$60 \mathrm{M}$ (cost-effectiveness greater than 1.15). These are the AS332L1 Super Puma (manufactured by Airbus Helicopters), the CH-47D Chinook (manufactured by Boeing), the Mi-17v5 (manufactured by Mil Moscow), and the S-61T (developed from the Sea King and manufactured by Sikorsky). ${ }^{2}$ While

Figure 1. Operating Bases (left) and Notional Targets (right)

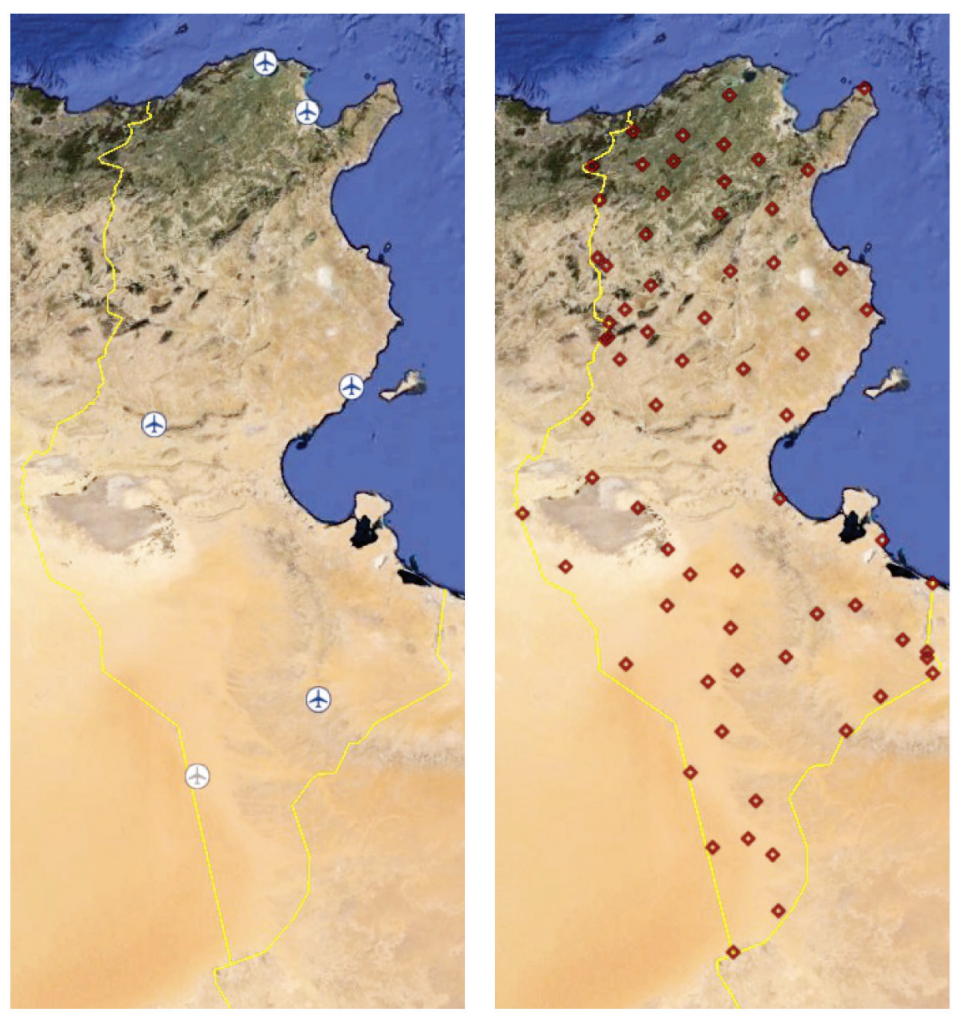

SOURCE: Google; map data from SIO, NOAA, U.S. Navy, NGA, GEBCO; image from Landsat, U.S. Department of State.

Figure 2. Examples of the Landing Zones
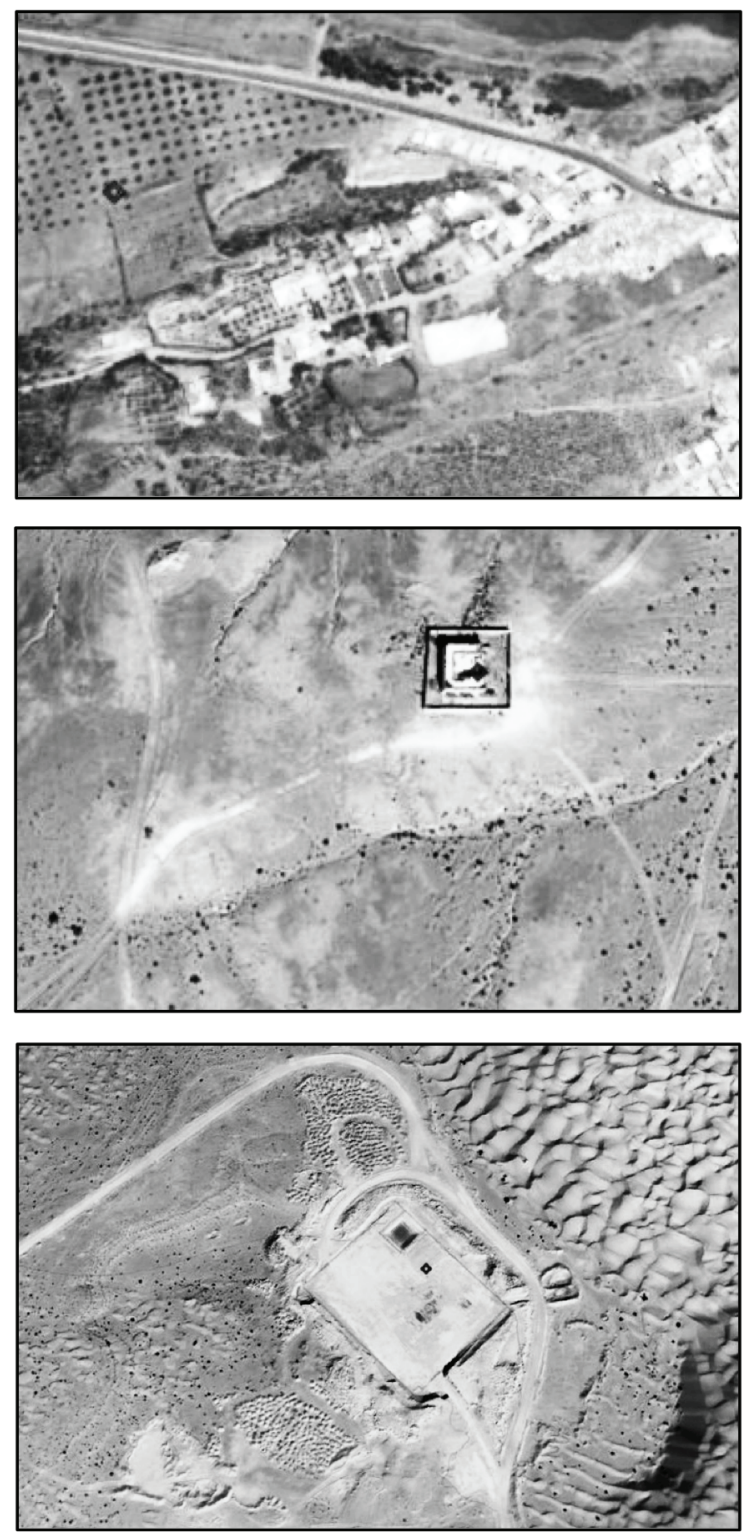

SOURCE: Google; image from DigitalGlobe. 
Figure 3. Cost-Effectiveness of Helicopter Options

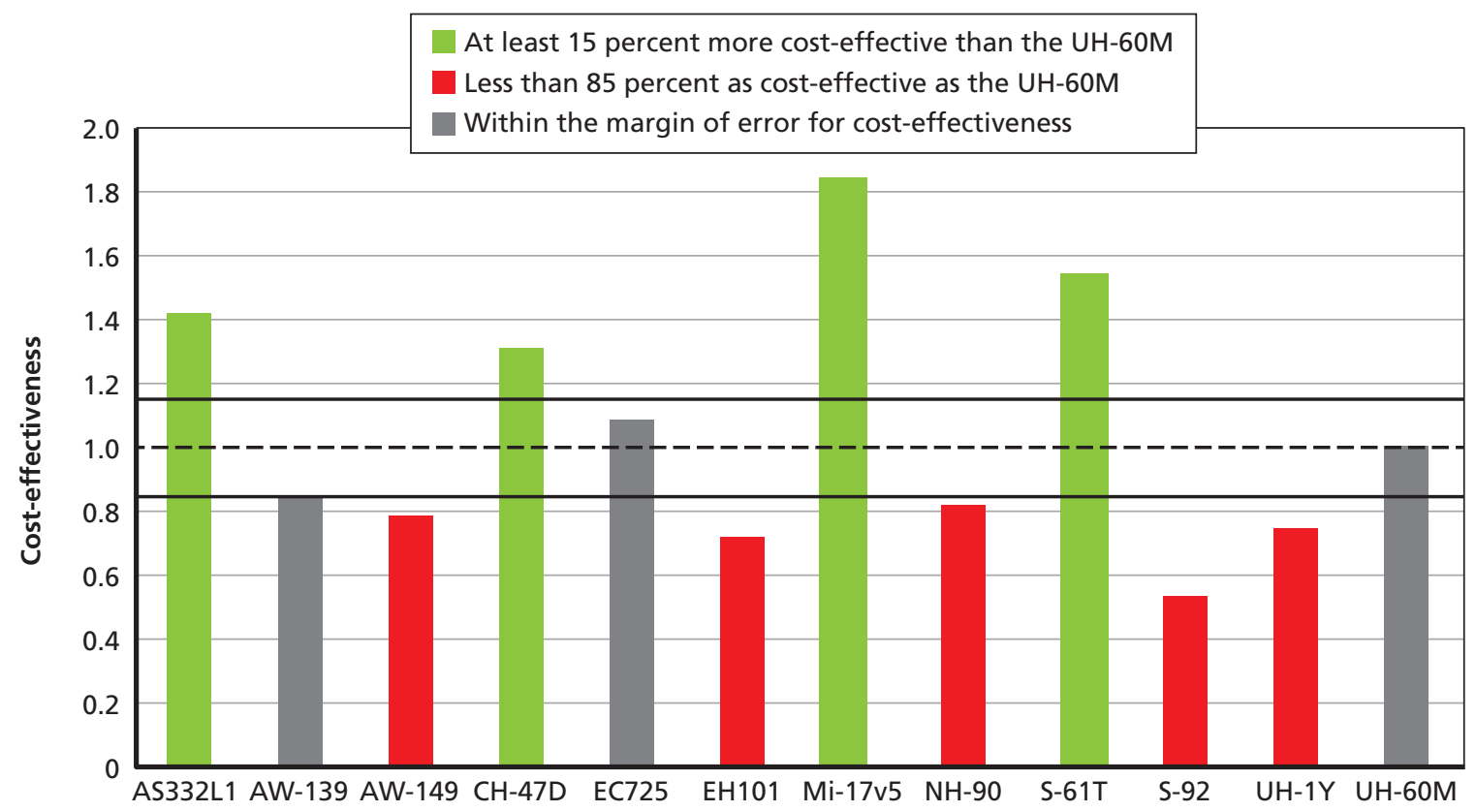

NOTE: Columns above the dashed line are more cost-effective than the UH-60M, and columns below the dashed line are less cost-effective. Columns between the two solid lines are within the margin of error of the analysis.

inside our margin of error, the EC725 Super Cougar (manufactured by Airbus Helicopters) also has the potential to be a more costeffective platform.

Helicopter platforms shown in green are at least 15 percent more cost-effective than the UH-60M, platforms shown in red are less than 85 percent as cost-effective, and options shown in gray are within the margin of error for cost-effectiveness. The A109M, Bell 412EP, EC145, and Bell Huey II (omitted from Figure 3) did not meet the minimum load of eight passengers on at least some of the mission; however, none would be a cost-effective option.

\section{Next Steps}

The results suggest that several alternative platforms could offer cost-effectiveness equal to or greater than the UH-60M. Depending on availability, they might offer viable alternatives to the UH-60M acquisition.

This analysis is preliminary and needs to be refined, based on a more precise definition of the mission set, basing locations, and target areas. The cost-effectiveness results shown in Figure 3 are driven, in part, by the specific mission-task assumptions, particularly the number of passengers. A broader set of mission tasks would likely change the precise cost-effectiveness comparisons across platforms but would likely not change the overall finding that there are cost-effective alternatives to the UH-60M in the Tunisian context. ${ }^{3}$ In addition, a complete sensitivity analysis should be conducted, to test whether the solution is being driven by any particular assumptions, including mission requirements.

The cost estimates were derived from past RAND research and do not reflect the most-recent pricing and mission-peculiar equipment. Since the delivery timeline is of prime concern, research into each manufacturer's backlog and production availability is needed. It would also be important to test these results with alternate mission, performance, and costing assumptions. 


\section{Notes}

${ }^{1}$ For a full discussion of the methodology and assumptions, see Christopher A. Mouton, David T. Orletsky, Michael Kennedy, Fred Timson, Adam Grissom, and Akilah Wallace, Cost-Effective Helicopter Options for Partner Nations, Santa Monica, Calif.: RAND Corporation, RR-141/1-OSD, 2015. As of December 29, 2015:

http://www.rand.org/pubs/research_reports/RR14lzl.html

${ }^{2} \mathrm{~A}$ key difference between the results of the current analysis and in Mouton et al., 2015, is the relative cost-effectiveness between the $\mathrm{CH}-47 \mathrm{D}$ and the Mi-17v5. In the previous research, the $\mathrm{CH}-47 \mathrm{D}$ was found to be more cost-effective than the Mi-17v5. In that analysis, company-sized movements ranged from 90 to 160 personnel (PAX), with 120 PAX being typical. The significantly larger PAX requirement meant that, absent other constraints, only three $\mathrm{CH}-47 \mathrm{Ds}$ would be required to complete a mission, versus five Mi-17v5s. In the current analysis, the PAX requirement is 50, which requires two $\mathrm{CH}-47 \mathrm{Ds}$ or two Mi-17v5s. This one-for-one trade between the $\mathrm{CH}-47 \mathrm{D}$ and $\mathrm{Mi}-17 \mathrm{v} 5$ is a direct consequence of the 50 PAX requirement, as 50 PAX is just over the capacity of a single $\mathrm{CH}-47 \mathrm{D}$ but exactly twice the capacity of a single Mi-17v5.

${ }^{3}$ A broader set of mission tasks would also decrease sensitivity to particular assumptions-see, e.g., note 2.

\section{About This Report}

This research was conducted within the Acquisition and Technology Policy Center of the RAND National Defense Research Institute, a federally funded research and development center sponsored by the Office of the Secretary of Defense, the Joint Staff, the Unified Combatant Commands, the Navy, the Marine Corps, the defense agencies, and the defense Intelligence Community.

For more information on the RAND Acquisition and Technology Policy Center, see http://www.rand.org/nsrd/ndri/ centers/atp.html or contact the director (contact information is provided on the web page).

\section{Limited Print and Electronic Distribution Rights}

This document and trademark(s) contained herein are protected by law. This representation of RAND intellectual property is provided for noncommercial use only. Unauthorized posting of this publication online is prohibited. Permission is given to duplicate this document for personal use only, as long as it is unaltered and complete. Permission is required from RAND to reproduce, or reuse in another form, any of our research documents for commercial use. For information on reprint and linking permissions, please visit www.rand.org/pubs/permissions.html.

For more information on this publication, visit www.rand.org/t/RR1410.

(C) Copyright 2016 RAND Corporation

The RAND Corporation is a research organization that develops solutions to public policy challenges to help make communities throughout the world safer and more secure, healthier and more prosperous. RAND is nonprofit, nonpartisan, and committed to the public interest.

RAND's publications do not necessarily reflect the opinions of its research clients and sponsors. RAND ${ }^{\circledR}$ is a registered trademark.

\section{wWw.rand.org}

